Article

\title{
Accessing Citizens' Perceptions of Land-Related Policy in a Social Media Setting: The Case of Rural Grazing Area Settlement Programme in Nigeria
}

\author{
Oluwafemi Adekola ${ }^{1, *(\mathbb{D}}$, Pauliina Krigsholm ${ }^{1,2} \mathbb{D}$ and Kirsikka Riekkinen ${ }^{1,2}$ (D) \\ 1 Department of Built Environment, School of Engineering, Aalto University, P.O. Box 12200 Aalto, Finland; \\ pauliina.krigsholm@aalto.fi (P.K.); kirsikka.riekkinen@aalto.fi (K.R.) \\ 2 Finnish Geospatial Research Institute, National Land Survey of Finland, Geodeetinrinne 2, \\ 02430 Masala, Finland \\ * Correspondence: Oluwafemi.adekola@aalto.fi
}

Citation: Adekola, O.; Krigsholm, P.; Riekkinen, K. Accessing Citizens' Perceptions of Land-Related Policy in a Social Media Setting: The Case of Rural Grazing Area Settlement Programme in Nigeria. Land 2022, 11, 200. https://doi.org/10.3390/ land 11020200

Academic Editor: Rohan Bennett

Received: 22 December 2021

Accepted: 25 January 2022

Published: 27 January 2022

Publisher's Note: MDPI stays neutral with regard to jurisdictional claims in published maps and institutional affiliations.

Copyright: (C) 2022 by the authors. Licensee MDPI, Basel, Switzerland. This article is an open access article distributed under the terms and conditions of the Creative Commons Attribution (CC BY) license (https:// creativecommons.org/licenses/by/ $4.0 /)$.

\begin{abstract}
Social media have opened interesting avenues for accessing active citizenry's perceptions, providing an important tool for the promotion of the successful implementation of policy. Although social media data have been used to access citizens' perceptions in various fields of study, they have yet to be adequately examined in the area of land-related policies. This study showcases the potential of the use of social media data to access citizens' perceptions of land-related policies in the context of a developing country. We systematically selected YouTube videos with expressions of citizens' perceptions of the Rural Grazing Area settlement programme in Nigeria. The findings from the social media data indicate that whilst some people perceived the policy's potential benefits, most expressed dissatisfaction with it, and some suggested alternative policy approaches. The results suggest that social media data may be a promising avenue for accessing citizens' opinions even in the case of land-related policies. Social media data must be accessed and used with caution, however, taking into consideration their limitations. This study's main contribution lies in the demonstration that social media data can provide valuable insights into citizens' perceptions of sensitive interventions, including land-related policies.
\end{abstract}

Keywords: citizen perception; social media; land-related policy

\section{Introduction}

In recent years, social media platforms such as Facebook, Twitter and YouTube have provided an accessible, affordable and ubiquitous space for the flow of ideas and opinions [1]. Social media have also been an incredible tool for individual empowerment in developing countries, where citizens have increasingly turned to such platforms to express their opinions and perceptions of issues that impact their lives [2]. The emergence of social media has also generated new opportunities for researchers and policymakers, specifically, opening interesting avenues for accessing citizens' perceptions of socioeconomic, environmental, scientific and political issues.

Citizens' perceptions can be defined as the ways in which the citizens of a given country or region (as individuals or a group) perceive specific issues or events that affect them, i.e., how they think about issues or events, understand them and form an impression of them [3]. Citizens' perceptions can have significant implications regarding the design and successful implementation of policy initiatives [4,5], and can be an important tool for increasing transparency, efficiency, accountability, good governance and trust $[6,7]$. Opinions shared on social media are often expressed by a generally active citizenry, and social media opinions are becoming increasingly important, emerging as a legitimate, influential expression of citizens' opinions [8]. Scholars in several disciplines have examined social media opinions in order to assess citizens' perceptions of, for example, public 
health policy [9], healthcare services [10], energy [11], and vaccinations [12]. Surprisingly, this emerging source of citizens' perceptions has yet to be adequately accessed for the understanding of citizens' perceptions of land-related policies.

Land-related policies are those associated with the land, such as land-use policy, agricultural policy and housing policy. Land-related policies are of critical importance in the achievement of sustainable development, good governance and economic growth, and in the mitigation of climate change and the alleviation of poverty, particularly in developing countries $[13,14]$. Through land-related policies, governments express their perception of the ways in which to solve land-related problems or challenges, such as unsustainable landuse management, inadequate land-use planning and land-natural resource conflicts [15]. Citizen's perceptions of land-related policies matter, as citizens are the major stakeholders in most policies, including land-related policies. In sub-Saharan Africa, for instance, the people are the main landholders, with around $90 \%$ of the land being under customary tenure, in which land is held by people in the community [16]. From this customary standpoint, most people consider land to be the basis not only of their economic livelihood but also their heritage, and part of their ancestral, spiritual and social identity [17]. These emotional and psychological attachments to land affect people's perceptions of and resulting reactions to land-related policies and reforms. For example, Shipton [18] notes that, in the context of African countries, attachment to land makes it impossible to mortgage or alienate land, as the citizens of these countries view the cultural features of the land as an inalienable heritage that cannot be sold. Consequently, a policy that promotes mortgages for credit accessibility may be unable to achieve its objectives. This highlights the importance of understanding citizens' opinions regarding land-related policies.

This study showcases the potential of social media as a data source for accessing citizens' perceptions of land-related policy in the context of a developing country. The study builds upon the case of a land-related policy in Nigeria, the 2019 Rural Grazing Area (RUGA) settlement programme (hereafter 'RUGA policy'), which attracted great attention and reactions from Nigerians. The RUGA policy was introduced to curb the persistent conflicts between farmers and herders over property rights and natural resource exploitation in Nigeria, but it did not receive the expected support of the people, and was suspended six weeks after its introduction due to the overwhelmingly negative citizen outcry. This study examines perceptions from that intense six-week period. With the RUGA policy, the government intended to use eminent domain to take over private/community land in some parts of the country for animal husbandry purposes, thus placing the policy on a wider scale with the potential to impact Nigerians as a whole (including farmers and herders). Foreseeing the potential impacts that the policy could have on their lives, the citizens approached social media platforms to express their opinions regarding the policy. We focused on YouTube, one of the more widely used social media and video platforms [19,20], on which Nigerians increasingly voice rich narratives that express opinions on political issues, providing a unique window into the perceptions of citizens.

We systematically collected YouTube videos of Nigerians expressing their perceptions of the RUGA policy during its implementation phase between 21 May 2019 and 3 July 2019, and we took an inductive thematic analysis approach to analyse the data and gain insights into the key recurring themes of the citizens' perceptions of the policy. The study's main contribution lies in showcasing the potential of the use of social media to access citizens' perceptions, even in the case of sensitive interventions such as land-related policies.

The remainder of the article proceeds as follows. The next section briefly discusses the use of social media as a data source, noting the associated benefits, biases and concerns. Next, the methodology section describes the case study policy and the study's data collection and analysis approach. Section 4 presents a descriptive analysis of the emergent themes and recurring themes of the citizens' perceptions of the policy, followed by a discussion in Section 5. Finally, Section 6 provides the concluding remarks. 


\section{Social Media as a Data Source for Citizens' Perceptions}

The assessment of citizens' perceptions is a challenging task [21], as perceptions can be complicated and distinctive. A person's perception at a given time does not necessarily represent their view at other times, making "simple analysis and generalisation problematic" [22] (p. 273). Consequently, there are no straightforward ways to access citizens' perceptions on a particular topic; as such, scholars have relied mainly on indirect methods, such as focus groups, surveys and content analysis [21]. Such methods have many strengths, but they can also be expensive and labour-intensive ways of collecting information.

Recently, researchers' attention has shifted towards the use of social media as a data source to accesscitizens' perceptions. Citizens are becoming actively engaged in policy issues, and social media provide a networked space for the formation, circulation and expression of citizens' opinions [1]. Because of the vast amount of information shared on social media, researchers now see social media as a fertile ground for accessing citizens opinions [23]. In fact, some scholars suggest that social media data have the potential to augment or replace the traditional survey methods of understanding citizens' opinions; see, for example, [24,25].

The opinions expressed on social media are generally from the more active citizenry [8], and these opinions often generate great interest from various stakeholders (in private and public institutions) because they can reveal insightful information that otherwise may not be observed [23]. For instance, Tumasjan et al. [26] used citizens' opinions expressed on Twitter as an indicator of political sentiment. They found that the opinions expressed on social media closely aligned with election results; see also $[27,28]$. Similarly, on policy issues, Barisione and Ceron [8] examined citizens' opinions on social media regarding austerity policies in three European countries. They note that social media provided a space for citizens to contest and mobilise against the governments' austerity policies. The study emphasises that social media empower the citizenry and afford citizens the opportunity to make their voices heard, even regarding policy issues.

Aside from uncovering insightful information, several other benefits may accrue from the gathering of citizens' opinions on social media. Social media data are timelier and less expensive to access than the traditional survey methods, generally comprising publicly available data that are easily accessible at close to zero cost, thus reducing the time, effort and money spent by researchers using social media content [24,25]. Additionally, studies have shown that people are becoming unwilling to participate in surveys-e.g., see [29] suggesting that the traditional survey method may become increasingly challenging due to changes in people's communication habits [30].

Social media data provide opportunities to study many topics-including citizens' perceptions - that may be hard to study by conventional research methods. There are, however, several limitations to be considered when using social media as a data source. The first is the methodological concern regarding the generalisability of social media data. While the number of social media users has increased over the years, many people still lack access to social media platforms [31]. In addition, most users are assumed to be passive and inactive [32], such that those users who do express opinions may not be representative of the population, making it necessary to be cautious in drawing inferences and conclusions from social media data [33].

The validity and reliability of social media data present additional challenges. The validity challenge is summarised, for example, by Mahrt and Scharkow [34], who note that big data, such as social media data, are useful to reveal what users do but not why they do it, thus limiting the questions that can be asked or answered using social media data [35]. Likewise, there are limitations related to the reliability of social media data. Social media data are governed by private companies, and not all of the interactions on a social media platform are shared. Social media platforms evolve in their settings, functionality and popularity (e.g., the composition of their user population fluctuates with current events and the rise and fall of other platforms), which affects the ways in which data are collected and analysed [33]. 
Aside from these methodological challenges, the use of social media as a data source brings legal and ethical concerns. Sometimes, social media data may contain sensitive personal information that must be handled carefully according to privacy laws (e.g., the EU countries' General Data Protection Regulation), and the nature of such legal and ethical guidelines may make it difficult to collect and analyse social media data [35]. Furthermore, from an ethical point of view, informed consent and anonymisation must also be considered. Typically, in qualitative research, it is essential for researchers to seek the informed consent of the participants whose data are used, but there is a lack of consensus regarding the ethical question of whether one must seek informed consent when using social media data, as those data are publicly available on social media platforms [36]. Furthermore, the anonymisation of a study's participants is important but may be impossible to fully ensure with social media data, as a simple text string might suffice to expose a participant's identity [37].

Because of these concerns and potential biases, a researcher's well-reasoned judgement is required when using social media as a data source $[33,38]$. Consequently, the highlighted biases and concerns were taken into consideration when collecting and analysing the data in this study. Most importantly, as in the case of all research, all of the limitations and considerations are reported along with the findings in order to prevent misinterpretation and enable the appropriate use of this study's findings.

\section{Methodology}

This section presents an overview of the case study's land-related policy, and describes the study's data collection and analysis.

\subsection{Case Study: Rural Grazing Area Settlement (RUGA) Policy}

Strife between farmers and herders remains a cause of persistent destructive conflict in Nigeria. Nomadic herders in search of pasture and water routinely clash with farmers whose crops are destroyed by their herds. These clashes occur in various part of the country, especially the north, and have often resulted in the loss of lives and property. According to the 2017 International Crisis Group report, thousands of civilians have lost their lives and tens of thousands have been displaced because of these persistent conflicts. The economic toll of the conflicts has been similarly huge [39]. Various solutions have been explored in order to resolve the persistent conflict, but none have yielded a desirable outcome. However, of great interest to this study is the recent policy introduced by the federal government of Nigeria, i.e., the RUGA policy, which attracted a great deal of attention from Nigerians.

On 11 May 2019, without consultation or the involvement of citizens in the policy process, the office of the Federal Government of Nigeria approved the RUGA policy, which sought to establish settlement areas for farmers involved in animal husbandry, particularly herders. The government intended to compulsorily acquire land from private/community landholders in various parts of the country, and to transform the land into settlements. These settlements were expected to be organised colonies with adequate basic infrastructure and amenities, such as road networks, veterinary clinics, markets, schools and hospitals. Starting with 12 pilot states, the programme was expected to be implemented in various states in Nigeria.

The office of the president of Nigeria envisioned the RUGA policy as a panacea for the persistent problem of conflict between herders and farmers, and that it would also boost the country's economy, but it did not foresee the degree of confrontation and mass rejection that the proposed programme met. The government touted several benefits that the policy could provide for Nigerians, including a drastic reduction in clashes between herders and farmers; a boost in animal production, quality and hygiene; accessible animal care; job creation; the reduction of cattle rustling; and access to credit facilities and private sector participation through investment. Despite the supposed benefits, the programme was suspended two months after its introduction. A concise timeline of the events surrounding the RUGA policy is given in Figure 1. Citizens' social media opinions during the policy's implementation are of particular interest in the context of this study. 


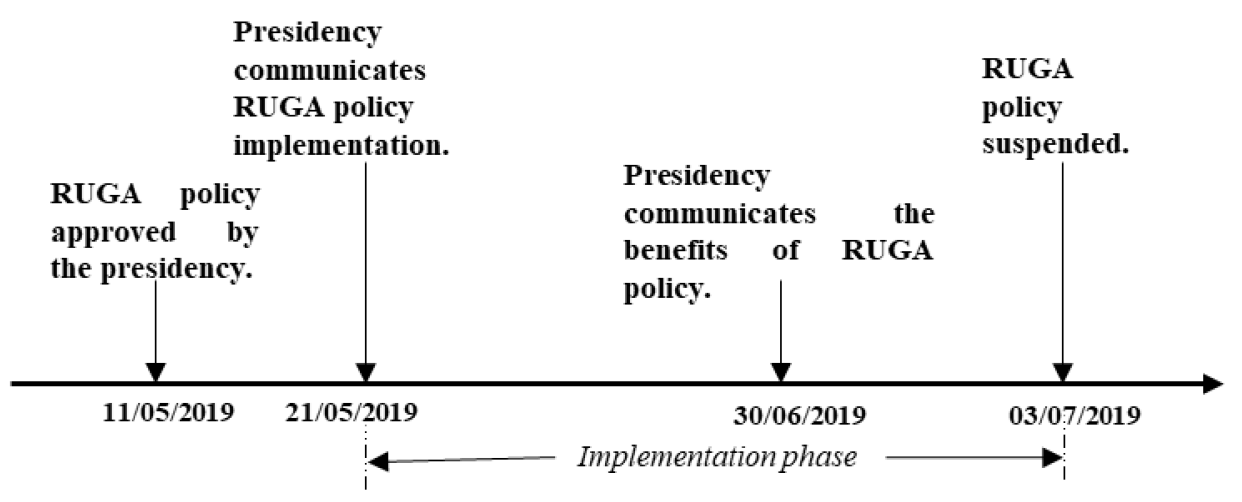

Figure 1. Timeline of the RUGA policy.

\subsection{Data Collection}

This study used YouTube-generated video clips as a data source, which served two major functions: (1) it captured people's perceptions during the policy implementation process, and (2) it provided naturally occurring data, which are believed to be preferable to researcher-generated data, which often suffer from "researcher effects", whereby the presence of a researcher influences the findings [40].

A systematic approach was taken in order to identify relevant videos generated on YouTube during the implementation phase of the RUGA policy in Nigeria (see Figure 2). Firstly, the YouTube database was queried using the following search terms: "RUGA policy in Nigeria", "RUGA settlement policy Nigeria" and "RUGA Nigeria". The initial search yielded 788 videos. The videos were then screened on the basis on their titles and when they were uploaded. Our focus was on perceptions expressed during the implementation phase of the RUGA policy (see Figure 1); as such, videos uploaded before 21 May 2019 or after 3 July 2019 were excluded, along with duplicate videos and videos with titles that were not relevant to the RUGA policy. This screening excluded 601 videos, reducing the number of eligible videos to 187.

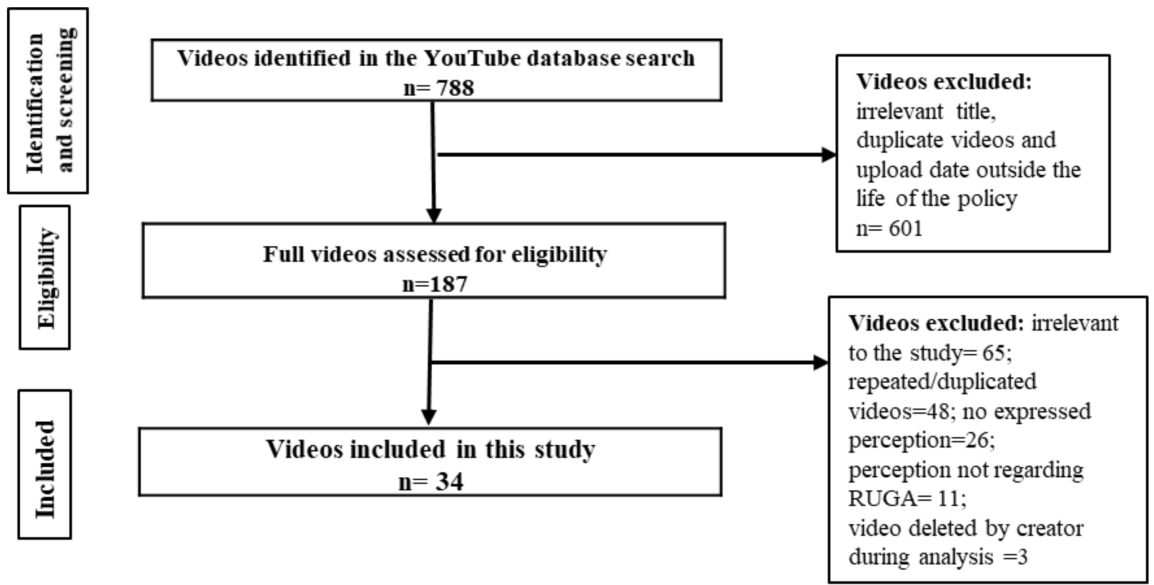

Figure 2. Flow diagram of the YouTube video selection process.

The resulting 187 videos were then fully assessed by watching each of them in order to identify those in which people expressed their opinions on the RUGA policy. This led to the exclusion of 153 more videos, including videos that had "RUGA" in their title but were not related to the RUGA policy (65 videos), duplicate videos and videos that were partial or full repetitions of other videos (48 videos), videos that did not include expressions of the perceptions of RUGA and videos that were not motivated by the RUGA policy (37 videos), and videos deleted by the creator during the analysis (3 videos). Ultimately, 34 YouTube videos were included in this study. The data were collected in February 2021. 
The included YouTube videos comprise two types: personal reaction videos and interview videos. In personal reaction videos (11 videos), YouTube users speak directly to viewers to share their opinions of the RUGA policy, while street and studio interview videos (23 videos) depict interviews conducted to elicit other people's opinions of the RUGA policy. The majority of the people in the videos are regular citizens (75) who wanted to air their opinions regarding the RUGA policy. In addition, there is a total of four government officials in the videos. These government officials are introduced in the videos as people holding political positions in the country. A summary of the properties of the included videos is given in Appendix A (Table A1).

Given the ethical concerns associated with social media data (see Section 2), we ensured the informed consent of the video creators by notifying the selected creators of the intention to use their videos in the study. The notifications were sent through email or by posting a comment when no email address was available. None of the creators asked to be excluded from the study.

\subsection{Data Analysis}

The included YouTube videos consist of Nigerians expressing their opinions of the RUGA policy at the time of the posting of the video. A playlist of the videos was generated, and they were studied intensively in order to identify each person's expressions regarding the RUGA policy. These expressions were carefully collected and transcribed verbatim. The transcripts were imported into Atlas.ti ${ }^{\mathrm{TM}}$ (version 8) for analysis.

The collected data were analysed with inductive thematic analysis, which offers a theoretically flexible approach to qualitative data analysis [41], and allows the data to directly inform the themes. The videos were watched, and the transcripts were read in order to understand the data, and to generate relevant codes that characterised and summarised people's expressed opinions and perceptions of the RUGA policy. The generated codes were then grouped by collating the related codes within a group. The codes within each group were organised and summarised into themes (subthemes), and related subthemes were further aggregated to form the major themes.

In order to ensure the trustworthiness and credibility of the analysis, researcher triangulation was used to refine the codes and themes. The generated themes were compared between the researchers, and no major differences were identified, but minor differences were resolved through discussion and consensus. Finally, the resulting themes were further re-examined against the codes in order to ensure consistency.

\section{Results}

Three broad themes in the citizens' perceptions of the RUGA policy emerged from the thematic analysis: policy benefits, policy objections and policy suggestions. This section first presents a descriptive analysis of the identified themes expressed in the data. Secondly, the detailed themes and respective subthemes that emerged from the thematic analysis of the data are presented.

\subsection{Descriptive Analysis of the Emergent Themes}

The average number of views for the 34 YouTube videos we assessed was 14,322 $(\min =10 ; \max =115,917)$. We extracted a total of 79 individuals' expressed perceptions of the RUGA policy from the 34 selected videos (see Section 3.2). Table 1 shows the themes and subthemes that emerged from the data, and the number of people associated with the respective thematic perceptions of the RUGA policy; it indicates that a majority (60 people) expressed disapproval or opposition to the RUGA policy. A total of 49 people recommended alternative approaches to solve farmer-herder conflicts. Finally, 21 people perceived that the RUGA policy could have some benefits. 
Table 1. Numbers of people and their expressed thematic perceptions.

\begin{tabular}{ccc}
\hline Theme & Subthemes & No. of People (n = 79) \\
\hline Policy benefits & $\begin{array}{c}\text { Economic contribution } \\
\text { Conflict prevention }\end{array}$ & 21 \\
Policy objections & Loss of valuable land \\
& Disregard for the rule of law & Security concerns \\
& Favouritism \\
Policy suggestions & Distrust in government \\
& Fear of hegemony \\
\hline & Alternative and localised solutions \\
& Focus on priority \\
\hline
\end{tabular}

The data show that people expressed mixed opinions of the RUGA policy. The diagram in Figure 3 illustrates how perceptions overlapped in the data. A total of 35 people expressed both objections and suggestions regarding the RUGA policy, five people mentioned both benefits and suggestions, one person described both objections and benefits, and finally, five people articulated opinions that included benefits, objections and suggestions. These results accentuate how complicated it can be to investigate opinions of land-related policy, as citizens often hold a mixture of opinions and interpretations regarding such policies.

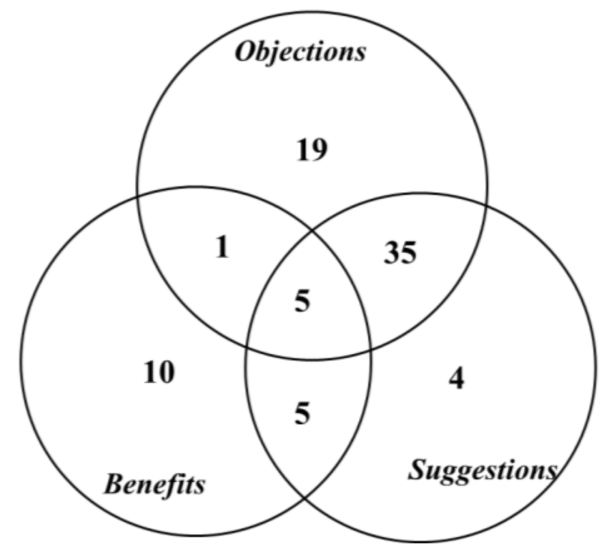

Figure 3. Venn diagram showing the numbers of people with overlapping perceptions of the RUGA policy.

\subsection{Citizens' Perceptions of the RUGA Policy}

Three broad themes emerged from the thematic analysis of citizens' perceptions of the RUGA policy: policy benefits, policy objections and policy suggestions. Table 1 shows the themes and subthemes that emerged from the data.

\subsubsection{Policy Benefits}

Economic contribution: Fourteen of the 21 people who mentioned perceived benefits articulated the potential economic benefit of the RUGA policy, opining that it could contribute immensely to the economic development of the nation. These people thought that setting up settlements for animal farmers could bolster the country's economy, improving and boosting the animal production segment of the agricultural sector by reducing imports and increasing exports of animal by-products (e.g., milk, meat, cheese and leather). A few people further stated that the programme could help the federation's states to improve their internally generated revenue, create job opportunities and ensure food security in the country. 
Conflict prevention: Beyond the perceived economic benefits, 20 people (out of the 21) viewed the settling of nomadic herders and their herds in a settlement as a welcome decision that could curb cattle rustling, limit cattle roaming around the country, and prevent disturbances or property damage to others (i.e., farmers). These people maintained that the policy could forestall the incessant killings and destruction of property that occur due to farmer-herder clashes in several parts of the country. Hence, they thought that the policy should be a top priority for the government in order to enable peace to reign in the country.

\subsubsection{Policy Objections}

Most of the people (60) who articulated their views raised objections to the policy, describing issues that made the RUGA policy unacceptable. Six subthemes emerged from these concerns: the loss of valuable land, security concerns, distrust in the government, favouritism, disregard for the rule of law, and the fear of hegemony.

Loss of valuable land: Twenty-six of the 60 objectors argued that the implementation of the policy would have a dire effect on the property rights of landowners. They noted that the policy would result only in the loss of limited land, and in depriving other land-users of the right to access the land. An opinion was also enunciated that some states lack enough land for farming, such that implementing a policy that takes over people's land for other purposes would not be prudent. These people saw the policy as a ploy by the presidency to grab land and invade their communities. To buttress these perceptions, one person said that "Land is not just a piece of land; [it] is spiritual, [it] is ancestral, [it] is political, [it] is historical and [it] means a lot. People go to war for land". These people noted that they could not approve of a policy that would eventually lead to the loss of their land.

Security concerns: Twenty-four objectors opined that the proposed policy would only escalate the country's current insecurity. According to this viewpoint, setting up herder settlements in several parts of the country would result in the extension of the incessant clashes, which mostly occur in the northern part, to the whole country. One person expressed that "peoples' lives matter", and that the security of lives should be the priority, not economic opportunity; this was also endorsed by someone else, who said that "It is said in [the] principle of existentialism that existence precedes essence; it is when you are [alive] that you can negotiate for how to live".

Distrust in the government: Twenty objectors claimed that the policy was a strategy to divert the attention of citizens; they also opined that the government had not really lived up to its promises. These people said that, despite the atrocities committed in the farmer-herder crisis, the government had failed to take responsibility and bring justice to the victims. The people noted that the government had been inadequate in fulfilling its most important duty, i.e., securing the lives and property of its citizens. In addition, they noted that the government could not be trusted to deliver as expected on the RUGA policy, because, in cases in which the government had claimed eminent domain, it had provided inadequate compensation. One person categorically stated that "the people have trust [issues] with the government", which reflected the people's widespread opposition to the RUGA policy.

Favouritism: Seventeen people who expressed dissatisfaction with the RUGA policy opined that the government had been overly interested in the affairs of the people in the northern part of the country. These people noted that "cattle herding is a private business", and argued that the government should not interfere in private business by trying to appropriate land all over the country for herders. They stated that, because the president is from the northern part of the country, the government had shown policy preferences in favour of his ethnic group, and against the interests of the country's other ethnic groups. To further express their dissatisfaction, these people noted that the president should be concerned about the affairs of the whole country, and should not focus solely on a particular faction.

Disregard for the rule of law: Of the 60 people who expressed disapproval of the RUGA policy, 17 claimed that the presidency was acting outside of its jurisdiction, as the 
law regulating the use of land in the country, i.e., the Land-use Act of 1978, confers on governors the power to administer land in all parts of their respective states. Thus, these people thought that it was not within the right of the office of the presidency to establish the RUGA policy without the states' involvement. In addition, some of these people noted that some states in the federation had already introduced laws to prohibit open grazing and encourage ranching. According to one statement, the federal government's attempt to introduce the RUGA policy was "a gross violation of state ranching law and an insult to the sensibilities of the states where the ranching law has been introduced".

Fear of hegemony: Others (10 persons) bluntly expressed the perception that the government was using the policy as a cover to establish hegemony and control the whole country through a particular ethnic group in the country (i.e., the Fulani ethnic group), calling the policy an attempt by the federal government to "Islamise and Fulanise [sic] the country".

\subsubsection{Suggestions Regarding the RUGA Policy}

The videos also included suggestions and recommendations of potential approaches that the government could use to solve the farmer-herder conflicts. The subthemes under this theme include alternative and localised solutions, the inclusion and education of stakeholders, and the need for the government to focus on another priority.

Alternative and localised solutions: Most people (35 people) who suggested a way forward argued that the policy would not solve the problem of persistent herder-farmer clashes. Rather, the government should seek better, alternative solutions. These people expressed that the farmer-herder conflicts are deeply rooted in the cultural differences between the parties involved in them; they recommended that the government locate the settlements in the northern part of the country, whence the herders often migrate from and where they share a similar way of life with the people. Additionally, some people stated that the policy should not be imposed on the states by the presidency. As an alternative, each state in the federation should choose whether to adopt the programme, with interested states being evaluated on the basis of their land conditions, land availability and capacity. Furthermore, a few people noted that the government should adopt better ideas for animal production from similar countries, such as Zimbabwe, Zambia and other African nations with prolific meat production.

Inclusion and education of stakeholders: Twenty-two people noted that the government did not engage or educate the necessary stakeholders in the policy-making process, and that the RUGA policy was not well understood by the people. The people who held this belief noted that the government should have educated both parties (i.e., farmers and herders) as well as the public before introducing the RUGA policy. One person stated that: "I felt that they [the federal government] should have spoken to the stakeholders, that is, the farmers, [and familiarise the farmers with] their plans regarding the RUGA [policy] and how it will work. Seek their input in it, get your buy-in and get them to come along with it".

Focus on priority: Eleven people said that the RUGA policy should not be the government's priority, as cattle herders are not the only ones who contribute to the economy. They opined that the government should instead be concerned about the insecurity, poverty and other problems ravaging the country. Someone described the RUGA policy as "a misplaced priority by the government". These people believed that, should the government address these other priority problems, the problem of farmer-herder clashes would be resolved simultaneously. In addition, they opined that the government should be more concerned about internally displaced persons who have been rendered homeless by the country's insecurity, and said that settlements should be prepared for such people rather than providing special settlements for herds. 


\section{Discussion}

This study demonstrates that social media data can provide valuable insights into citizens' perceptions regarding land-related policies. Our findings portray a spectrum of citizens' perceptions of the RUGA policy. While some people perceived the RUGA policy to be beneficial to Nigeria and its future development, most people voiced the opposite view, i.e., that the RUGA policy was unacceptable. This finding of mixed citizen perceptions reflects one of the challenges and complexities which is unique to devising land-related policies, i.e., an inability to adequately balance the interests of all stakeholders - see [42,43] which often leads to land-related policies that benefit some people to the detriment of others [44].

The social media data also provided access to rich narratives of citizens' opinions. We found that, beyond explicitly expressing their objections or support of the policy, the people in the selected videos suggested various potential alternatives and approaches by which the government could solve the farmer-herder crisis. These findings suggest that, by assessing the perceptions expressed by the active citizenry on social media, it is possible to identify sensitive opinions and feedback that policymakers could use to improve the policy process. Additionally, the findings further point out the need for policymakers to endeavour to engage active citizenries in the governance of land, which can be crucial to the success of land policies, and can promote the ownership of the policy and encourage transparency and accountability, among other things [45].

While this study's approach appears promising, certain limitations must be noted concerning the use of social media data, particularly in this study. Firstly, the results revealed that some citizens believed that the RUGA policy was made for the benefit of only a certain ethnic group in the country. In a country with various ethnic groups, this finding suggests that ethnicity may have played a significant role in the perception of the RUGA policy, with members of the allegedly "favoured" ethnic group accepting the policy while members of other ethnic groups mobilised (albeit through social media) to reject the policy. This shows that the citizens' opinions expressed in this study may have resulted from a cascade of influences in which individuals' opinions were influenced by others in their immediate social media circle [46]. Social media can be used to propagate widespread (mis)information that may be used to manipulate users' emotions and influence their perceptions [47], and this limitation could be a source of bias in studies using social media data. Hence, subsequent studies using social media data could suggest ways of controlling for this possible source of bias.

Secondly, this study used the expressed perceptions of people who appeared in videos uploaded to YouTube. The sample size was relatively small, and, consequently, the citizens ${ }^{\prime}$ perceptions presented in this study cannot be generalised to the entire Nigerian population. This notwithstanding, the study did not aim to generalise its findings but instead to offer insights on citizens' perceptions expressed on social media regarding the RUGA policy. Similarly, we note that there is very little background information available on the citizens whose expressed perceptions were presented in this study (see Table 1). Therefore, there is no way to fully determine the motivations or ideologies that drove their expressed opinions. Although this type of concern is inherent in qualitative research and cannot be fully avoided, more detailed information about the citizens would have enabled a more informed interpretation of the results.

Finally, we stress that the perceptions considered in this study were expressed around the time of the implementation phase of the RUGA policy. At that phase, citizens were becoming aware of precisely what the policy entailed, and were reacting and responding to the changes. Consequently, it is important to point out that it is uncertain whether the method used in this study could be applied at the planning phase of a policy. At that phase, presumably, people are to some extent unaware of the form the policy is taking, such that they would be unlikely to express their views as actively as during the implementation phase. Hence, data on citizens' perceptions may not be as easily available in the planning phase as in the implementation phase of a policy. In addition, while this study has presented 
the potential benefits of the use of social media data to access citizens' perception regarding the RUGA policy, we suggest that future studies should expand the scope of analysis by combining social media data analysis with additional methods, such as interviews with government officials, in order to enable the evaluation of the implementation effect of the policy.

\section{Conclusions}

This study demonstrates that social media data can be used to gain valuable insights into citizens' perceptions of land-related policy, providing access to organic data and rich narratives of citizens' perceptions of policies. With the growing use of social media, particularly in developing countries, we may assume that, in due course, it will be increasingly possible for both for scholars and policymakers to use social media to access citizens' perceptions for the purposes of land-related policymaking. Hence, this study can serve as a reference for future studies using social media to access and collect citizens' perceptions of land-related policies. However, the social media data must be accessed and used with caution due to the limitations inherent in the use of such data.

This study contributes to the literature on land-related policies in developing countries. In addition, the study showcases the potential of the use of social media as a source of data for accessing citizens' perceptions, even in the case of sensitive interventions such as land-related policies. The method proposed in this study could provide practical means by which policymakers can access information on citizens' perceptions, which could serve as a catalyst for policymakers to improve existing policy processes and deepen their insights into the ways in which people perceive land-related policies, and into the factors that contribute to those perceptions, providing policymakers with information that will help them target services in the most appropriate manner.

Author Contributions: Conceptualization, O.A., P.K. and K.R.; methodology, O.A.; validation, O.A., P.K. and K.R.; formal analysis, O.A.; investigation, O.A.; resources, O.A., P.K. and K.R.; data curation, O.A; writing — original draft preparation, O.A.; writing—review and editing, O.A., P.K. and K.R.; visualization, O.A., P.K. and K.R.; supervision, P.K. and K.R.; project administration, K.R.; funding acquisition, K.R. All authors have read and agreed to the published version of the manuscript.

Funding: This research is funded by Aalto University School of Engineering, Finland.

Informed Consent Statement: Informed consent was obtained from all subjects involved in the study.

Data Availability Statement: The data presented in this study are available on request from the corresponding author. The data are not publicly available due to privacy.

Acknowledgments: We gratefully acknowledge the support of Aalto University School of Engineering, Finland. Special thanks also go to the independent researcher who helped with the researcher triangulation of the results presented in this study. In addition, we appreciate the anonymous reviewers whose comments and suggestions have been insightful in improving this study.

Conflicts of Interest: The authors declare no conflict of interest. 


\section{Appendix A}

Table A1. Summary of the videos included for the study.

\begin{tabular}{|c|c|c|c|c|}
\hline S/No. & No. of People & Mode of Expression & Views & Time \\
\hline 1 & 1 & personal & 469 & $29 ; 30$ \\
\hline 2 & 1 & interview & 5157 & $21 ; 40$ \\
\hline 3 & 1 & personal & 69,785 & $21 ; 27$ \\
\hline 4 & 5 & Interview (2 streets) & 6942 & $17 ; 26$ \\
\hline 5 & 2 & interview & 115,917 & $34 ; 00$ \\
\hline 6 & 1 & interview & 18,486 & $15 ; 27$ \\
\hline 7 & 2 & interview & 28,219 & $22 ; 46$ \\
\hline 8 & 1 & interview & 11,605 & $26 ; 10$ \\
\hline 9 & 2 & interview & 2082 & $6 ; 54$ \\
\hline 10 & 2 & Interview (street) & 58 & $31 ; 44$ \\
\hline 11 & 1 & personal & 2132 & $12 ; 21$ \\
\hline 12 & 1 & personal & 897 & $22 ; 55$ \\
\hline 13 & 1 & interview & 34 & $23 ; 25$ \\
\hline 14 & 1 & personal & 1301 & $13 ; 49$ \\
\hline 15 & 1 & personal & 10 & $2 ; 15$ \\
\hline 16 & 1 & interview & 288 & $3 ; 26$ \\
\hline 17 & 1 & personal & 246 & $8 ; 27$ \\
\hline 18 & 1 & interview & 60,640 & $22 ; 57$ \\
\hline 19 & 2 & interview & 31,625 & $23 ; 56$ \\
\hline 20 & 1 & interview & 18,843 & $22 ; 33$ \\
\hline 21 & 12 & Interview (street) & 1422 & $16 ; 45$ \\
\hline 22 & 1 & personal & 56 & $5 ; 19$ \\
\hline 23 & 1 & personal & 157 & $1 ; 41$ \\
\hline 24 & 1 & interview & 52,111 & $17 ; 41$ \\
\hline 25 & 8 & Interview (street) & 6941 & $9 ; 22$ \\
\hline 26 & 2 & Interview & 770 & $15 ; 08$ \\
\hline 27 & 1 & personal & 459 & $4 ; 52$ \\
\hline 28 & 2 & interview & 371 & $1 ; 58$ \\
\hline 29 & 3 & Interview (street) & 138 & $4 ; 42$ \\
\hline 30 & 7 & interview & 16,394 & $51 ; 29$ \\
\hline 31 & 2 & interview & 30,576 & $20 ; 40$ \\
\hline 32 & 5 & Interview (3 streets) & 499 & $2 ; 47$ \\
\hline 33 & 4 & Interview (street) & 1581 & $3 ; 08$ \\
\hline 34 & 1 & personal & 741 & $5 ; 03$ \\
\hline
\end{tabular}

\section{References}

1. Sobkowicz, P.; Kaschesky, M.; Bouchard, G. Opinion mining in social media: Modeling, simulating, and forecasting political opinions in the web. Gov. Inf. Q. 2012, 29, 470-479. [CrossRef]

2. Ali, A.H. The power of social media in developing nations: New tools for closing the global digital divide and beyond. Harv. Hum. Rts. J. 2011, 24, 185-219.

3. Kassens-Noor, E.; Wilson, M.; Cai, M.; Durst, N.; Decaminada, T. Autonomous vs. Self-Driving Vehicles: The Power of Language to Shape Public Perceptions. J. Urban Technol. 2020, 28, 5-24. [CrossRef]

4. Fan, Y. A Research about Public Participation in the Process of Master-Urban-Planning in China-An Introduction of Practice of Gathering Public Opinion via Questionnaire Survey. Adv. Appl. Sociol. 2015, 5, 13-22. [CrossRef]

5. Morgan, M.G. Public perception, understanding, and values. In the Industrial Green Game: Implications for Environmental Design and Management; Richards, D.J., Ed.; National Academy Press: Washington, DC, USA, 1997; pp. 200-211.

6. OECD. Focus on Citizens: Public Engagement for Better Policy and Services; OECD: Paris, France, 2009; pp. $300-322$.

7. Clifton, J.; Díaz-Fuentes, D. Evaluating eu policies on public services: A citizens' perspective. Ann. Public Coop. Econ. 2010, 81, 281-311. [CrossRef]

8. Barisione, M.; Ceron, A. A Digital Movement of Opinion? Contesting Austerity Through Social Media. In Social Media and European Politics; Barisione, M., Michailidou, A., Eds.; Palgrave Macmillan: London, UK, 2017; pp. 77-104.

9. Kang, Y.; Wang, Y.; Zhang, D.; Zhou, L. The public's opinions on a new school meals policy for childhood obesity prevention in the US: A social media analytics approach. Int. J. Med. Inform. 2017, 103, 83-88. [CrossRef]

10. Hu, G.; Han, X.; Zhou, H.; Liu, Y. Public Perception on Healthcare Services: Evidence from Social Media Platforms in China. Int. J. Environ. Res. Public Health 2019, 16, 1273. [CrossRef] 
11. Li, R.; Crowe, J.; Leifer, D.; Zou, L.; Schoof, J. Beyond big data: Social media challenges and opportunities for understanding social perception of energy. Energy Res. Soc. Sci. 2019, 56, 101217. [CrossRef]

12. Raghupathi, V.; Ren, J.; Raghupathi, W. Studying Public Perception about Vaccination: A Sentiment Analysis of Tweets. Int. J. Environ. Res. Public Health 2020, 17, 3464. [CrossRef]

13. Deininger, K.W. Land Policies for Growth and Poverty Reduction. A World Bank Policy Research Report; World Bank Publications: Washington, DC, USA, 2003; pp. 215-239.

14. D'Aquino, P.; Bah, A. Land Policies for Climate Change Adaptation in West Africa: A Multilevel Companion Modelling Approach. Simul. Gaming 2012, 44, 391-408. [CrossRef]

15. Chigbu, U.E.; Enemark, S.; Zevenbergen, J. Improving the Mode of Academic Networking to Scale up Land Education in Africa. In Proceeding of FIG Working Week 2020 Smart Surveyors for Land and Water Management, Amsterdam, The Netherlands, 10-14 May 2020.

16. Chimhowu, A. The 'new' African customary land tenure. Characteristic, features and policy implications of a new paradigm. Land Use Policy 2019, 81, 897-903. [CrossRef]

17. Gilbert, J. Custodians of the land: Indigenous peoples, human rights and cultural integrity. In Cultural Diversity, Heritage and Human Rights: Intersections in Theory and Practice; Langfield, M., Logan, W., Craith, M., Eds.; Routledge: London, UK, 2010; pp. 31-44.

18. Shipton, P.M. Mortgaging the Ancestors: Ideologies of attachment in Africa; Yale University Press: New Haven, CT, USA; London, UK, 2009; pp. 1-352.

19. Statista: Most Popular Social Networks Worldwide as of October 2020, Ranked by Number of Active Users. Available online: https:/ / www.statista.com/statistics/272014/global-social-networks-ranked-by-number-of-users/ (accessed on 18 December 2020).

20. Statista: Forecast of the number of YouTube users in Nigeria from 2017 to 2025. Available online: https: / /www.statista.com/ forecasts / 1144636/youtube-users-in-nigeria (accessed on 1 November 2021).

21. Dowler, E.; Green, J.; Gasperoni, C. Assessing public perception: Issues and methods. In Health, Hazards and Public Debate: Lessons from BSE/CJD Saga; Dora, C., Ed.; WHO Regional Office for Europe: Copenhagen, Denmark, 2006; pp. 39-60.

22. Scott, A. Assessing Public Perception of Landscape: The LANDMAP experience. Landsc. Res. 2002, 27, 271-295. [CrossRef]

23. Chatzakou, D.; Vakali, A. Harvesting Opinions and Emotions from Social Media Textual Resources. IEEE Internet Comput. 2015, 19, 46-50. [CrossRef]

24. Schober, M.F.; Pasek, J.; Guggenheim, L.; Lampe, C.; Conrad, F.G. Social Media Analyses for Social Measurement. Public Opin. Q. 2016, 80, 180-211. [CrossRef]

25. Conrad, F.G.; Gagnon-Bartsch, J.; Ferg, R.A.; Schober, M.; Pasek, J.; Hou, E. Social Media as an Alternative to Surveys of Opinions About the Economy. Soc. Sci. Comput. Rev. 2019, 39, 489-508. [CrossRef]

26. Tumasjan, A.; Sprenger, T.; Sandner, P.; Welpe, I. Predicting elections with twitter: What 140 characters reveal about political sentiment. In Proceedings of the International AAAI Conference on Web and Social Media, Washington, DC, USA, 23-26 May 2010; Volume 4.

27. Sang, E.T.K.; Bos, J. Predicting the 2011 Dutch senate election results with twitter. In Proceedings of the Workshop on Semantic Analysis in Social Media, Avignon, France, 23 April 2012; pp. 53-60.

28. Jensen, M.J.; Anstead, N. Psephological investigations: Tweets, votes, and unknown unknowns in the republican nomination process. Policy Internet 2013, 5, 161-182. [CrossRef]

29. Brick, J.M.; Williams, D. Explaining Rising Nonresponse Rates in Cross-Sectional Surveys. Ann. Am. Acad. Polit. Soc. Sci. 2012, 645, 36-59. [CrossRef]

30. Schober, M.F.; Conrad, F.G.; Antoun, C.; Ehlen, P.; Fail, S.; Hupp, A.; Johnston, M.; Vickers, L.; Yan, H.Y.; Zhang, C. Precision and Disclosure in Text and Voice Interviews on Smartphones. PLoS ONE 2015, 10, e0128337. [CrossRef]

31. Statista: Global Social Network User Growth from 2018 to 2026. Available online: https: / /www.statista.com/statistics/270919 /worldwide-social-network-user-growth/ (accessed on 1 November 2021).

32. van Dijck, J. Users like you? Theorizing agency in user-generated content. Media Cult. Soc. 2009, 31, 41-58. [CrossRef]

33. Ruths, D.; Pfeffer, J. Social media for large studies of behavior. Science 2014, 346, 1063-1064. [CrossRef]

34. Mahrt, M.; Scharkow, M. The Value of Big Data in Digital Media Research. J. Broadcast. Electron. Media 2013, 57, 20-33. [CrossRef]

35. Lomborg, S.; Bechmann, A. Using APIs for Data Collection on Social Media. Inf. Soc. 2014, 30, 256-265. [CrossRef]

36. Patterson, A.N. YouTube Generated Video Clips as Qualitative Research Data: One Researcher's Reflections on the Process. Qual. Inq. 2018, 24, 759-767. [CrossRef]

37. Lomborg, S. Personal internet archives and ethics. Res. Ethics 2012, 9, 20-31. [CrossRef]

38. Staff, C.; King, H.; Roberts, M.; Pannell, S.; Roberts, D.; Wilson, N.; Mann, R.; Cooper, A. Using Social Media for Social Research: An Introduction; Social Science in Government; Social Media Research Group: London, UK, 2016; pp. 1-23. Available online: http:/ / dera.ioe.ac.uk/id/eprint/26600 (accessed on 1 November 2021).

39. International Crisis Group. Herders against Farmers: Nigeria's Expanding Deadly Conflict. Africa Report; International Crisis Group (ICG): Brussels, Belgium, 2017; pp. 1-31. Available online: https://www.refworld.org/docid/59c21a454.html (accessed on 1 November 2021).

40. Jonathan, P. Discourse Analysis as a Way of Analysing Naturally Occurring Talk. In Qualitative Research: Theory, Method and Practice, 2nd ed.; Silverman, D., Ed.; SAGE Publications: London, UK, 2004; pp. 200-221. 
41. Braun, V.; Clarke, V. Using thematic analysis in psychology. Qual. Res. Psychol. 2006, 3, 77-101. [CrossRef]

42. Pottier, J. Land Reform for Peace? Rwanda's 2005 Land Law in Context. J. Agrar. Chang. 2006, 6, 509-537. [CrossRef]

43. Collins, A.; Mitchell, M.I. Revisiting the World Bank's land law reform agenda in Africa: The promise and perils of customary practices. J. Agrar. Chang. 2017, 18, 112-131. [CrossRef]

44. Adekola, O.; Krigsholm, P.; Riekkinen, K. Towards a holistic land law evaluation in sub-Saharan Africa: A novel framework with an application to Rwanda's organic land law 2005. Land Use Policy 2021, 103, 105291. [CrossRef]

45. Grover, R.; Törhönen, M.P.; Palmer, D.; Munro-Faure, P. Good Governance in Land Tenure and Administration; Food \& Agriculture Organization of the UN (FAO): Rome, Italy, 2007; Volume 9, pp. 1-57, ISBN 9789251057537.

46. Bakshy, E.; Messing, S.; Adamic, L.A. Exposure to ideologically diverse news and opinion on Facebook. Science 2015, 348, 1130-1132. [CrossRef]

47. Wu, L.; Morstatter, F.; Carley, K.M.; Liu, H. Misinformation in Social Media: Definition, Manipulation, and Detection. ACM SIGKDD Explor. Newsl. 2019, 21, 80-90. [CrossRef] 